\title{
Characterization of sea water ageing effects on mechanical properties of carbon/epoxy composites for tidal turbine blades
}

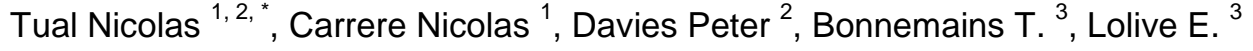 \\ ${ }^{1}$ LBMS/ENSTA-Bretagne, 29200 Brest, France \\ 2 Ifremer, Marine Structures Laboratory, 29280 Plouzané, France \\ ${ }^{3}$ LBMS/IUT Brest Dept. GMP rue de Kergoat 29200 Brest, France \\ * Corresponding author : Nicolas Tual, email address : nicolas.tual@ensta-bretagne.org \\ nicolas.carrere@ensta-bretagne.fr ; peter.davies@ifremer.fr ; thomas.bonnemains@univ-brest.fr ; \\ eric.lolive@univ-brest.fr
}

\begin{abstract}
:
In recent years, many tidal turbine projects have been developed using composites blades. Tidal turbine blades are subject to ocean forces and sea water aggressions, and the reliability of these components is crucial to the profitability of ocean energy recovery systems. The majority of tidal turbine developers have preferred carbon/epoxy blades, so there is a need to understand how prolonged immersion in the ocean affects these composites. In this study the long term behaviour of different carbon/epoxy composites has been studied using accelerated ageing tests. A significant reduction of composite strengths has been observed after saturation of water in the material. For longer immersions only small further changes in these properties occur. No significant changes have been observed for moduli nor for composite toughness. The effect of sea water ageing on damage thresholds and kinetics has been studied and modelled. After saturation, the damage threshold is modified while kinetics of damage development remain the same.
\end{abstract}

Keywords : Carbon-epoxy, Sea water ageing, Mechanical testing, Diffusion 
1. Introduction

Over the last 50 years composite materials have found many applications in the maritime domain, particularly in the yachting and offshore energy industries [1], [2], [3],[4]. Composite materials are used in many offshore structures and new applications are being developed such as tidal turbine blades. Tidal turbines offer an exciting opportunity to exploit ocean current flows to generate energy. The interest in the use of composite materials for tidal energy convertor structures is based on the potential improvements in hydrodynamic and structural performance. In addition to the advantages of high strength-to-weight and strength-to stiffness ratios, the anisotropy of the composites can be designed to allow three dimensional tailoring of the blade deformation [5]. The reliability of these components, in a very severe environment, is crucial to the profitability of tidal current energy systems.

These structures are subject to many forces such as ocean tides, waves, storms but also to various marine aggressions, such as sea water and corrosion. It was estimated [6] for a $1 \mathrm{MW}$ turbine operating in a 4.5 knot tide that 900 tons/s of water pass through the turbine rotor. Structures for tidal energy must also be designed to withstand transient forces caused by turbulence and passing surface waves. As a consequence, mechanical loads on marine energy converters are cyclic (due to the motion of the waves for wave energy converters or the action of tides on tidal turbines). A thorough understanding of the fatigue behavior of the moving parts (example: turbine blades) is therefore essential. A previous study [7], [8], has highlighted the sensitivity of durability to the choice of components (fibre, resin, surface treatment of fibres). That work was carried out on thin composites reinforced by glass fibres. However, the majority of tidal turbine developers (MCT SeaGen, Alstom/TGL, Atlantis, Sabella...) have preferred carbon blades and the composite thicknesses are very large, especially in the area of connection between blade and hub. Under these conditions, sea water can induce changes in carbon/epoxy composite materials [9], [10]. The absorption of water molecules in polymer composites is known to have important effects on their final performance [11] [12], especially in their long-term exploitation [13], [14]. By the 
organic nature of the matrix resin, often an epoxy, long immersion in sea water can induce both physical and chemical changes [15]. Plasticization and swelling are the main physical consequences of water absorption on polymer structures [16], [17]. The plasticization corresponds to a modification of the structure of the polymer and results in a decrease of the glass transition temperature [18], [19]. It also induces loss of mechanical properties with a reduction in moduli and failure stress. Swelling of the matrix is caused by the penetration of water into polymers, as a consequence volume changes will occur. At the composite scale, swelling can create interfacial cracks and fibre/matrix debonding [20]. Transverse cracking (intra-laminar) is the principal damage mechanism in uni-directional composite laminates loaded off-axis. A transverse crack is often followed by debonding at the plies interface. This micro-debonding can have a major influence on both transverse cracking saturation [21] and on the composite out-of-planestrength [22]. As a result, the lifetime of composites will be dominated by their interlaminar or out-ofplane response. When composites are immersed at sea, water is first absorbed at the surface and then diffuses into the material. Some analogies between heat transfer and mass diffusion were established by Fick [23] in order to determine the kinetics of water entry into composites. Experimentally it is also possible to follow water concentration in polymer and composite materials. There are various experimental methods but the simplest and definitely the most popular is based on sample weight measurements dry $\left(\mathrm{w}_{0}\right)$ then in wet $(\mathrm{w})$ conditions throughout the immersion time of the samples. It is then possible to determine the water mass fraction : $\mathrm{m}=\left(\mathrm{w}-\mathrm{w}_{0}\right) / \mathrm{w}_{0}$ and quantify the diffusion behaviour of water in a composite material [15]. The kinetics of diffusion can change during the service life of composites in operation, damage due to the diversity of mechanical loads may impact and accelerate the diffusion of water inside the composite structures, as damage can create new pathways for water entry [24], [25].

Sea water ageing in the tidal turbine environment, at ocean temperature, will generate a slow process of degradation and damage in composites. Therefore there is a need to develop a procedure to accelerate ageing in order to assess the long term in-service behaviour of composites to be used in the marine environment. Accelerated testing is also a valuable tool for rapid comparison of different material options. As a 25-year lifetime requirement is commonly specified in the renewable marine energy industry, the accelerated test protocol must aim to reproduce the effects of 25 years exposure in a few months [26]. 
The purpose of this paper is to characterize and model the long term behaviour of different carbon/epoxy composites for tidal turbine blade applications. First, the characterization of the carbon/epoxy composites will be presented using standardized tests after different sea water ageing times. For this characterization, the sea water ageing process has been accelerated through immersion at higher temperature than ocean conditions. Second, a damage model taking into account the crack development in composite materials will be discussed. Finally, methods to identify and validate the model during the accelerated ageing will be presented.

2. Materials and methods

In order to evaluate the influence of sea water ageing on composite materials for tidal turbine blades, static, quasi-static and cyclic tests have been performed on different candidate materials. Some cyclic test results will be presented subsequently, but a preliminary investigation has already been described [27], here only results from static and quasi-static tests will be discussed.

2.1. Materials

Tidal turbine blades can be manufactured using different processes and materials. For example, Gurit manufactured blades for the HS1000 turbine [28] based on a spar cap moulded with unidirectional carbon prepreg and glass prepreg. The outer shells are all glass prepreg and all components were oven-cured. In another approach, Norco has successfully manufactured three very large tidal turbine blades for The Atlantis Resources Corporation [29], which have now been in service for some time, using vacuum infused epoxy resin processing. Airborne Marine has produced blades for Tocardo and Nautricity using Resin Transfer Moulding (RTM), [30].

In this study three processes and materials have been chosen to produce samples for tests: 
i) A carbon reinforced epoxy pre-preg manufactured using the autoclave process, this pre-preg could be used in blade spars. The samples were produced by FMC Composites in Brest. The UD prepreg layers are composed of HexPly® M21 matrix and UD HexTow® IMA (UD194 12K) carbon fibres. Pre-preg curing conditions were respected following product data specifications. Full vacuum was applied on composites, then a 7 bar autoclave pressure at $180^{\circ} \mathrm{C}$ for 120 minutes.

ii) A carbon reinforced epoxy made by resin transfer moulding (RTM), provided by Airborne Marine. The RTM material could be used in blade body and blade spar elements. Airborne has already used the RTM process to manufacture one shot tidal turbine blades. The fibre is a standard carbon one and the matrix is a marine optimised epoxy resin. Information and details about Airborne material are protected by industrial confidentiality.

iii) A carbon reinforced epoxy manufactured by vacuum infusion, this material could be used to manufacture the blade body. This carbon epoxy was manufactured in the LBMS Laboratory, using Tenax-E IMS65 E23 24K carbon and the same epoxy resin as the RTM material. The samples were made on a glass plate, with a vacuum of 0.95 bars for the infusion process. All the plates have been cured at $65^{\circ} \mathrm{C}$ for 16 hours

This choice of material reflects the different current possibilities for manufacturing tidal turbine blades. It also allows the impact of fibre, matrix, and interface on the ageing mechanisms to be studied. Some details about the material composition are presented in

Table 1. For this study, materials were produced with different orientations and thicknesses.

As the specimen cutting method can affect composite mechanical and diffusion properties, all specimens tested were cut using the same high pressure water jet cutting method.

\subsection{Quality control}

An initial series of quality tests was performed, both to check the quality of each material and to obtain reference values for mechanical properties before ageing. 
Thus all composites panels were checked using DSC (Differential Scanning Calorimetry) to verify the state of cure before putting the materials in circulating natural sea water temperature baths. A TA Instruments Q200 DSC was used with a heating rate of $10{ }^{\circ} \mathrm{C} /$ minute. The glass transition temperature (Tg) is useful to determine the maximum sea water ageing temperature for accelerated conditions. Table 2, shows the results. As sea water ageing can affect the material glass transition (Tg), additional DSC measurements were also used to follow the evolution of the Tg during the immersion of composites in sea water.

Measurements were performed with a helium pycnometer in order to check the density of each type of material, using two specimens of approximately $10 \times 30 \times \mathrm{h} \mathrm{mm}^{3}$ (where $\mathrm{h}$, is the thickness) for each material. Density measurements allow fibre content to be estimated if it is assumed that there is no porosity. Table 3 shows the results.

Interlaminar shear strength tests (ILSS) were performed according to NF EN 2563, to check that materials were well impregnated. Samples were $10 \mathrm{~mm}$ wide and tested under displacement control at $2 \mathrm{~mm} / \mathrm{minute}$; an acceptance criterion of $45 \mathrm{MPa}$ was defined, above that value we can consider that the material is correctly impregnated. This criterion is based on experience from various previous studies at Ifremer. Different orientations and thicknesses were studied, for each condition three specimens were tested. Results are presented in Table 4.

Figure 1 shows optical microscope images taken to check composite quality and identify the different phases of the material (e.g. nodules, stitching fibres). These will also be used as a reference to check the influence of ageing. An estimation of the porosity level was made by image analysis of optical microscope images, and was found to be below 1\% for all materials. Figure 2 shows an example of a porosity measurement for a RTM UD. It is important to make this analysis because porosity can create preferential pathways for water diffusion. 


\subsection{Gravimetric analysis}

Water uptake can affect the properties, so in order to develop predictive models of property changes through the laminate the diffusion kinetics must be quantified, e.g. [31].

Sea water ageing was performed on each material at different temperatures. Specimens of each material, with different thicknesses and material orientations, were cut from composite plates by water jet cutting, 3 specimens per condition of $50 \times 50 \times$ thickness $\mathrm{mm}^{3}$. Then those samples were measured and weighed and finally distributed in four natural circulating sea water tanks at different temperatures: 25, 40, 60 and $80^{\circ} \mathrm{C}$. Temperature was continuously monitored and controlled to $\pm 1.5^{\circ} \mathrm{C}$. The water uptake was determined as a percentage of the initial weights of specimens, based on regular weight measurements made during ageing .

\subsection{Mechanical tests}

The characterization of elastic properties was performed using tensile tests on $90^{\circ}$ and $0^{\circ}$ laminates at a crosshead displacement rate of $2 \mathrm{~mm} / \mathrm{min}$, according to ISO 527, before and during different steps of sea water ageing. For the determination of mode I fracture toughness, DCB (Double Cantilever Beam) specimens were used in accordance with ISO 15024. The loading was introduced through bonded aluminium tabs, on an electro-mechanical testing machine at a constant displacement rate of $1 \mathrm{~mm} / \mathrm{min}$; all tests were filmed. Due to possible instability of the crack initiation from the implanted starter film a short mode I pre-crack was introduced in each specimen. Figure 11 (a) shows an example of the DCB load-displacement plots recorded during pre-cracking and propagation for two pre-preg material specimens. On first loading (dotted lines) there is a sudden unstable load drop during pre-crack introduction from the film. When the specimens were reloaded (continuous lines) the crack advanced in a stable manner from the pre-crack. Image analysis was used using Matlab ${ }^{\mathrm{TM}}$ Measuretool for measuring crack lengths under mode I conditions. 
Interlaminar Shear Stress (ILSS) tests were also used to follow the evolution of interfacial adhesion during ageing, according to EN ISO 14130.

At least three specimens of each material per condition per test type were prepared and tested in the wet state.

In addition to interlaminar crack behaviour another mode of damage studied after aging was inter-fibre tensile cracking using tensile loading on $0 / 90^{\circ}$ laminates [32]. Samples $\left(25 \times 150 \mathrm{~mm}^{2}\right)$ of the infused and the pre-preg composites with a $\left[0_{2}, 90_{2}\right]_{\mathrm{s}}$ stacking sequence were aged and tested on an electro-mechanical testing machine. All samples were tested wet at $1 \mathrm{~mm} / \mathrm{min}$ after allowing them to cool for one hour in sea water at room temperature. One side of the specimens was painted white to improve observation of the cracks. The crack development was followed using two high definition cameras, (Eco655MVGE (2448x2050 pixels) cameras with Computar TEC-M55 lens), Figure 3. We assume that once a crack is created, it takes place across the whole thickness and width [33],[34].

Coupled with this visual analysis, acoustic emission (AE) was also used to follow crack initiation and propagation in the specimens. AE measurements were used in order to determine precisely the threshold of damage. To follow damage development MISTRAS Micro II equipment was used with two NANO 30 sensors. The AE sensors were monitored with a threshold at 55-60 db and correlated with the load signal, one was placed at each end of the specimen. Images of the two cameras were then assembled to obtain the complete surface of the specimen. The images were processed to subtract noise. Figure 4 represents the visualisation of cracks after image treatment. The cracks were then counted automatically using Matlab ${ }^{\mathrm{TM}}$ software by differentiating levels of grey.

3. Results

3.1. Diffusion of sea water 
Examples of mean weight gain plots versus the square root of immersion time at $25^{\circ} \mathrm{C}, 40^{\circ} \mathrm{C}, 60^{\circ} \mathrm{C}$ and $80^{\circ} \mathrm{C}$, are shown in Figure 5 for UD RTM samples.

These materials have been immersed for 7500 hours. The diffusion kinetics can be fitted to a Fickian law. For each material, a stable weight gain is noted, after about 900 hours at $60^{\circ} \mathrm{C}$ for infused material, 1600 hours at $80^{\circ} \mathrm{C}$ for pre-preg and 2400 hours at $60^{\circ} \mathrm{C}$ for the RTM material. Figure 6 , presents some results of water uptake measurement for the three materials (only UD orientation). The weight gains at the two highest temperatures stabilize at a higher saturation level than for the two lower conditions. This may be due to the evolution of the glass transition temperature during ageing. For lower temperatures as $40^{\circ} \mathrm{C}$ and $25^{\circ} \mathrm{C}$, a stable weight gain is still not achieved after 14 months in water.

As tidal turbine blades could be manufactured using thick carbon epoxy laminates, it was important to compare the influence of the thickness on sea water diffusion, so a comparison between RTM 2.5 and 5 mm unidirectional (UD) materials was performed. Results presented in Figure 7 (a), highlight that diffusion kinetics and rate of water uptake are independent of the thickness of the composite. Other experimental investigations were conducted to examine the influence of specimen geometry, Figure 7 (b). Specimens of UD of different surface dimensions, 50 x 50, 25 x 100, and $100 \times 25 \mathrm{~mm}^{2}$, were immersed. Water diffusion parameters were not influenced by the geometry of the specimen, suggesting that it is the through-thickness diffusion $\left(D_{z}\right)$ which is dominating under these conditions. The influence of the thickness, orientation and geometry has been widely treated in the literature showing that the diffusion process is generally independent of those parameters [13],[35]. However some parameters such as porosity and fibre rate do influence water diffusion in composites [36],[37],[38]. Coefficients of Fickian diffusion for UD composite materials are presented in Table 6.

\subsection{Accelerated ageing conditions}


In service, tidal turbine blades in shallow water are exposed to sea water at temperatures from 10 to $25^{\circ} \mathrm{C}$, thus to allow short term tests to assess long term exposure at lower temperature, tests were performed here at higher temperature. However, it is important to age the materials below their glass transition temperatures, presented in Table 2. Therefore Infused and RTM materials were aged at $60^{\circ} \mathrm{C}$ and Prepreg material at $80^{\circ} \mathrm{C}$. The times to saturate the composites in sea water were determined using diffusion curves, and those times will be the starting point for physical and mechanical tests.

3.3. Effect of sea water ageing on in-plane material properties

For the three materials, a characterization of the mechanical properties was performed with tensile tests on specimens cut from UD panels at $90^{\circ}$ and $0^{\circ}$ after saturation. Three samples were tested in the wet state at $20^{\circ} \mathrm{C}$ for each condition (specimen dimensions $25 \times 250 \times$ thickness $\mathrm{mm}^{3}$, following ISO 527 specifications), all cut using a water jet. Water uptake has a particularly large effect on strengths, Figure 9, first due to matrix plasticization [15], which increases failure strain, followed by reductions due to fibre/matrix interface changes. No significant effects on moduli have been observed, Figure 8. On Figure 8, scatter bands are not represented because they are very small, between 1 and $4 \%$. For strengths, coefficients of variation are between 4 and $13 \%$ for all three materials with no significant difference between them. In order to examine the plasticisation phenomenon unreinforced resin samples were aged and tested,

Figure 10 (b). The modulus of the matrix is significantly reduced after ageing when tests are performed on wet specimens but when specimens are dried to constant weight before testing the modulus returns to its initial unaged value. Additionally some specimens of each composite material were aged under the same time and temperature conditions but dry, in an oven. For example in Table 5 a comparison is presented for dry and wet aged composite specimens. In the dry (oven) aging condition no significant change in strength was observed, indicating that it is the effect of water rather than temperature which dominates the degradation. 


\subsection{Effect of seawater on interlaminar shear strength}

ILSS tests are often used for monitoring quality and are suitable for the comparison of materials. These tests provide information about the quality of the resin-fibre bond. The procedure only indicates apparent shear properties, as peak stresses occur near to the loading point. The evolution of the interlaminar shear strength during ageing has been followed for different material orientations and thicknesses.

According to Figure 10 (a), the decrease of interlaminar shear strength in both cases is quite important, about $20-30 \%$ for UD materials. A parallel study on unreinforced resin shows no irreversible drop in tensile strength after saturation. So it is reasonable to conclude that the interfacial adhesion in all three carbon/epoxy composites is affected by sea water ageing.

\subsection{Effect of sea water ageing on composite toughness}

The change in composite materials toughness has been investigated using DCB tests during ageing. DCB tests were performed on un-aged material, then after three different ageing times. The effect of water ageing on the propagation toughness is quite limited, as shown in Figure 11 (b).

3.6. Effect of seawater on transverse crack density

The development of intraply damage was studied by inter-fibre tensile cracking in tension on infused cross-ply composites in the dry state and after 900 and 1600 hours' immersion at $60^{\circ} \mathrm{C}$. The normalized crack density is the relation between the number of cracks, the observation length and the $90^{\circ}$ plies thickness, this is the number of cracks divided by the observation length and multiplied by the thickness of the considered ply. In Figure 12, the change in the normalized crack density as a function of the 
applied stress for three different ageing times is presented for a $\left[0_{2}, 90_{2}\right]_{\mathrm{s}}$ laminate. The red squares represent three non aged specimens, blue triangles correspond to specimens aged for 37 days (saturation) and the green circles to specimens aged for 67 days (saturation plus one month). Figure 12 shows that the threshold of damage decreases after 37 days of ageing and remains more or less constant for longer ageing periods. The kinetics of the crack density development (i.e. the evolution of the number of cracks as a function of the applied load) are not influenced by the ageing. Indeed, the curves corresponding to the different ageing times are only shifted horizontally but have the same shape.

The threshold of the appearance of transverse cracks under tensile loading can be described by the criterion proposed in (1) by Hashin [39]:

$$
f_{2}^{+}=\left(\frac{\left\langle\sigma_{22}\right\rangle_{+}}{Y_{i s}^{t}}\right)^{2}+\left(\frac{\sigma_{12}}{S_{i s}^{12}}\right)^{2} \text { with }\left\{\begin{array}{l}
\langle X\rangle_{+}=X \text { if } X>0 \\
\langle X\rangle_{+}=0 \text { if } X<0
\end{array}\right.
$$

$Y_{i s}^{t}$ is the in-situ transverse tensile strength. $S_{i s}^{12}$ is the in-situ in-plane shear strength. It has been shown in [40] that the in-situ strength differs from those measured on a UD ply, and can be obtained using the expressions below (2):

$$
\left\{\begin{array}{l}
Y_{i s}^{t}=1.12 \sqrt{2} Y^{t} \text { for thick plies } \\
Y_{i s}^{t}=\sqrt{\frac{8 G_{I}^{c, p l y}}{\pi t \Lambda_{22}^{0}}} \text { for thin plies }
\end{array}\right.
$$

Where $t$ is the thickness of the ply, and $Y_{i s}^{t}$ the strength measured on a $\left[90_{\mathrm{n}}\right]$ laminate. $G_{I}^{c, p l y}$ is the mode I critical strain energy release rate. This toughness can be identified using the threshold of the damage measured on a cross-ply laminate with a thin $90^{\circ}$ ply. Indeed, in this case, the damage threshold is a function of the toughness (see (2)). The macroscopic load $\Sigma^{\text {nuc }}$ leading to the initiation of the first transverse crack is very easy to detect with Acoustic Emission. Using the classical laminate theory, it is 
possible to calculate the transverse stress in the $90^{\circ}$ ply. This stress is equal to the in-situ strength $Y_{i s}^{t}$. The actual in-situ strength is the minimum of the two strengths calculated in (2). Using this stress in (2), one obtains:

$$
G_{I}^{c, p l y}=\frac{1}{8}\left(\sigma_{22}^{i n}\right)^{2} \pi t \Lambda_{22}^{0}
$$

The parameter $\Lambda_{22}^{0}$ is given by (4):

$$
\Lambda_{22}^{0}=2\left(\frac{1}{E_{22}}-\frac{v_{12}^{2}}{E_{11}}\right)
$$

Where $E_{11}, E_{22}$ are the moduli values and $v_{12}$ is the Poisson's ratio. A similar formula exists for the in-situ in-plane shear strength. The in-situ strength provided by this approach is shown in Figure 13.

Following the approach proposed by Hashin [41] the increase in the number of cracks could be described by a finite-fracture approach as:

$$
W(N+\Delta N)-W(N)=G_{p l y}^{c} * \Delta N * S_{f}^{2+}
$$

Where $\mathrm{W}(\mathrm{N})$ is the elastic energy in the laminate with $\mathrm{N}$ cracks, $\mathrm{W}(\mathrm{N}+\Delta \mathrm{N})$ is the elastic energy in the laminate with $\mathrm{N}+\Delta \mathrm{N}$ cracks. $S_{f}^{2+}$ is the surface of a transverse crack $\left(S_{f}^{2+}=L \times w\right.$, see Figure 14). The only material parameter that needs to be identified is the toughness of the ply $\mathrm{G}_{\text {ply }}^{\mathrm{C}}$ (see [42] for details). 
Following equations (2) to (5) it is possible to describe the change in the threshold of damage as a function of the ageing time. Indeed, for the composite under investigation, the damage threshold is controlled by the stress criterion of the as-received material $\left(\mathrm{Y}_{\mathrm{t}}=43 \mathrm{MPa}, \mathrm{G}_{\mathrm{ply}}^{\mathrm{C}}=0.2 \mathrm{~N} / \mathrm{mm}\right.$ leading to $Y_{i s}^{t}$ $=72 \mathrm{MPa})$. At saturation, the strength measured on a $\left[90^{\circ}\right]$ laminate decreases drastically while the toughness and moduli values remain constant $\left(\mathrm{Y}_{\mathrm{t}}=27, \mathrm{G}_{\mathrm{Ic}}=0.2\right)$. In this case, the in-situ strength is controlled by the toughness and is equal to $38 \mathrm{MPa}$. Finally, for the ageing corresponding to saturation plus one month, $\left(\mathrm{Y}_{\mathrm{t}}=23, \mathrm{G}_{\mathrm{ply}}^{\mathrm{C}}=0.2\right)$, the in-situ strength remains constant and equal to $38 \mathrm{MPa}$. It is interesting to note that the reduction in damage threshold, Figure 12, and the ILSS results, Figure 10a, follow a similar trend. There is an initial strength drop when water enters the material, about $25 \%$ for both tests, but no further change with immersion time (at least for the test durations here). This trend and the resin results suggest that the fibre/matrix interface may be controlling both tests for this material, but more wok is required to investigate coupling between water diffusion and mechanical loads.

Once the failure criterion is fulfilled, the number of cracks can increase, and this increase is mainly controlled by the toughness. Since, $\mathrm{G}_{\text {ply }}^{\mathrm{C}}$ remains constant as a function of the ageing, the kinetics of crack propagation are not modified. The curves corresponding to the kinetics of crack development as a function of the applied load for the three ageing times are simply shifted along the load axis.

\section{Conclusion}

Throughout their service life, tidal turbine blades will be subjected to many marine aggressions, in particular due to sea water penetration into their composite components. The kinetics of the entry of water have been studied for three candidate materials for tidal turbine blades. Different material orientations and thicknesses were used to characterize the water diffusion behaviour at different temperatures for those materials. It has been shown that thickness and orientation have little influence on the kinetics of diffusion of water in these materials. However, the manufacturing process and the type of matrix resin do affect both the kinetics of water absorption into these composites and the water saturation state. The diffusion of sea water into the composite materials has a particularly severe effect on static mechanical strength characteristics. A decrease of $20 \%$ to $40 \%$ in failure strengths was measured, but no significant effects on the elastic moduli have been observed. Sea water ageing has only a small effect on the 
toughness $\mathrm{G}_{\mathrm{Ic}}$, of these composites, though ILSS tests indicated that interfacial adhesion under shear loading is affected. The study has enabled the limits of the accelerated aging method based on increasing water temperature to be identified. For the prepreg composite this approach is valid, and allows long term properties to be estimated. For the two composites based on the lower $\mathrm{Tg}$ resin this approach is questionable, as excessively high temperature $\left(60^{\circ} \mathrm{C}\right)$ introduces unrepresentative aging mechanisms such as oxidation. While extrapolation of mechanical test data to longer times may then be conservative, these data cannot be used to make quantitative predictions of property changes for lower temperatures.

A damage model was developed in order to characterize the influence of sea water ageing on the appearance and propagation of damage. Two criteria are both necessary conditions for damage in composites, one criterion based on stress and the other on energy. The identification of these criteria was based on the transverse strength and the toughness of the ply $\mathrm{G}_{\mathrm{Ic}}$. As only the stress criterion evolves during sea water ageing, the energy criterion will drive the kinetics of damage after the saturation of the composites by sea water. But there will be a shift to lower loads in the onset of damage after sea water ageing. Damage and cracks that appear in the composite will create new pathways for the diffusion of water, and this could also modify the kinetics of diffusion. It is therefore necessary to examine coupling between water diffusion and the evolution of properties and damage appearance in composites during sea water ageing, in order to improve the prediction of long time behaviour of composites immersed in sea water. Their response to cyclic loading is also being studied.

\section{Acknowledgements}

This research was partially supported by the Bretagne region. We thank Airborne Marine for providing RTM composite materials, finally we thank Malick Diakahate for his technical assistance with acoustic emission measurements. 
References

[1] W. C. Tucker and T. Juska, "Marine Applications," in Handbook of Composites, S. T. Peters, Ed. Springer US, 1998, pp. 916-930.

[2] D. W. Chalmers, "The Potential for the use of composite materials in marine structures," Mar. Struct., vol. 7, no. 2-5, pp. 441-456, 1994.

[3] C. S. Smith, Design of marine structures in composite materials /. London; Elsevier Applied Science, c1990.

[4] A. P. Mouritz, E. Gellert, P. Burchill, and K. Challis, "Review of advanced composite structures for naval ships and submarines," Compos. Struct., vol. 53, no. 1, pp. 21-42, Jul. 2001.

[5] R. F. Nicholls-Lee, S. R. Turnock, and S. W. Boyd, "Performance prediction of a free stream tidal turbine with composite bend-twist coupled blades," presented at the 2nd International Conference on Ocean Energy (ICOE 2008), 2008.

[6] G. Marsh, “Tidal turbines harness the power of the sea,” Reinf. Plast., vol. 48, no. 6, pp. 44-47, Jun. 2004.

[7] A. Boisseau, P. Davies, and F. Thiebaud, "Sea Water Ageing of Composites for Ocean Energy Conversion Systems: Influence of Glass Fibre Type on Static Behaviour,” Appl. Compos. Mater., vol. 19, no. 3-4, pp. 459-473, Jun. 2012.

[8] A. Boisseau, P. Davies, and F. Thiebaud, "Fatigue Behaviour of Glass Fibre Reinforced Composites for Ocean Energy Conversion Systems,” Appl. Compos. Mater., vol. 20, no. 2, pp. 145-155, Apr. 2013.

[9] C.-H. Shen and G. S. Springer, "Effects of Moisture and Temperature on the Tensile Strength of Composite Materials,” J. Compos. Mater., vol. 11, no. 1, pp. 2-16, Jan. 1977.

[10] G. S. Springer, Environmental effects on composite materials. Technomic Pub. Co., 1981.

[11] P. Davies, F. MazÉas, and P. Casari, "Sea Water Aging of Glass Reinforced Composites: Shear Behaviour and Damage Modelling,” J. Compos. Mater., vol. 35, no. 15, pp. 1343-1372, Aug. 2001. 
[12] A. Kootsookos and A. P. Mouritz, "Seawater durability of glass- and carbon-polymer composites," Compos. Sci. Technol., vol. 64, no. 10-11, pp. 1503-1511, Aug. 2004.

[13] H. S. Choi, K. J. Ahn, J.-D. Nam, and H. J. Chun, "Hygroscopic aspects of epoxy/carbon fiber composite laminates in aircraft environments," Compos. Part Appl. Sci. Manuf., vol. 32, no. 5, pp. 709720, May 2001.

[14] R. Martin, "Introduction,” in Ageing of Composites, R. Martin, Ed. Woodhead Publishing, 2008, pp. xix-xxiii.

[15] X. Colin and J. Verdu, "Humid Ageing of Organic Matrix Composites," in Durability of Composites in a Marine Environment, P. Davies and Y. D. S. Rajapakse, Eds. Springer Netherlands, 2014, pp. 47114.

[16] E. L. McKague, J. D. Reynolds, and J. E. Halkias, "Swelling and glass transition relations for epoxy matrix material in humid environments," J. Appl. Polym. Sci., vol. 22, no. 6, pp. 1643-1654, Jun. 1978.

[17] Y. J. Weitsman, Fluid Effects in Polymers and Polymeric Composites. Springer Science \& Business Media, 2011.

[18] P. Musto, M. Galizia, G. Scherillo, and G. Mensitieri, "Water Sorption Thermodynamics in Polymer Matrices," in Durability of Composites in a Marine Environment, P. Davies and Y. D. S. Rajapakse, Eds. Springer Netherlands, 2014, pp. 15-45.

[19] B. De'Nève and M. E. R. Shanahan, "Water absorption by an epoxy resin and its effect on the mechanical properties and infra-red spectra," Polymer, vol. 34, no. 24, pp. 5099-5105, Dec. 1993.

[20] U. Gaur and B. Miller, "Effects of environmental exposure on fiber/epoxy interfacial shear strength," Polym. Compos., vol. 11, no. 4, pp. 217-222, Aug. 1990.

[21] J. A. Nairn and S. Hu, "The initiation and growth of delaminations induced by matrix microcracks in laminated composites,” Int. J. Fract., vol. 57, no. 1, pp. 1-24, Sep. 1992.

[22] J. Charrier, "Développement de méthodologies dédiées à l'analyse robuste de la tenue de structures composites sous chargements complexes tridimensionnels.," Thèse, ENSAM Paris, 2013. 
[23] C.-H. Shen and G. S. Springer, "Moisture Absorption and Desorption of Composite Materials," J. Compos. Mater., vol. 10, no. 1, pp. 2-20, Jan. 1976.

[24] O. Gillat and L. J. Broutman, "Effect of an external stress on moisture diffusion and degradation in a graphite-reinforced epoxy laminate,” ASTM Spec. Tech. Publ., no. 658, pp. 61-83, 1978.

[25] S. Roy and W. Xu, "Modeling of diffusion in the presence of damage in polymer matrix composites,” Int. J. Solids Struct., vol. 38, no. 1, pp. 115-126, Jan. 2001.

[26] P. Davies, “Accelerated Aging Tests for Marine Energy Applications," in Durability of Composites in a Marine Environment, P. Davies and Y. D. S. Rajapakse, Eds. Springer Netherlands, 2014, $165-177$.

[27] N. Tual, N. Carrère, P. Davies, T. Bonnemains, and E. Lolive, "Characterization of Sea Water Ageing Effects on Mechanical Properties of Cabon/Epoxy Composites for Tidal Turbine Blades" presented at the ECCM-16th European Conference on Composite Materials, Seville, Spain, 2014.

[28] J. Sloan, "Tidal turbine blade toughened for turbulent salt sea.," Composites World, vol. 18, no. 6, p. 48, Dec-2012.

[29] Norco GRP Ltd, "Atlantis Marine Tidal Turbines," Norco specialise in GRP and Composite Mouldings. http://www.norco.co.uk/Capabilities/atlantis-marine-tidal-turbines/.

[30] Airborne Marine, Customer base for reliable tidal blades. http://airborne-marine.com/reliable-tidalblades/composite-blades-for-tidal-turbines/.

[31] A. Siriruk and D. Penumadu, "Effect of Sea Water on Polymeric Marine Composites," in Durability of Composites in a Marine Environment, P. Davies and Y. D. S. Rajapakse, Eds. Springer Netherlands, 2014, pp. 129-142.

[32] F. Laurin, N. Carrère, and J.-F. Maire, "A multiscale progressive failure approach for composite laminates based on thermodynamical viscoelastic and damage models," Compos. Part Appl. Sci. Manuf., vol. 38, no. 1, pp. 198-209, Jan. 2007.

[33] K. W. Garrett and J. E. Bailey, "Multiple transverse fracture in $90^{\circ}$ cross-ply laminates of a glass fibre-reinforced polyester,” J. Mater. Sci., vol. 12, no. 1, pp. 157-168, Jan. 1977. 
[34] J.-M. Berthelot, P. Leblond, A. El Mahi, and J.-F. Le Corre, "Transverse cracking of cross-ply laminates: Part 1. Analysis,” Compos. Part Appl. Sci. Manuf., vol. 27, no. 10, pp. 989-1001, 1996.

[35] R. M. V. G. K. Rao, M. Chanda, and N. Balasubramanian, "A Fickian Diffusion Model for Permeable Fibre Polymer Composites,” J. Reinf. Plast. Compos., vol. 2, no. 4, pp. 289-299, Oct. 1983.

[36] C. D. Shirrell and F. A. Sandow, "The Kinetics of Moisture Diffusion in Three Advanced Composite Epoxy Resin Matrix Material Systems," in Fibrous Composites in Structural Design, E. M. Lenoe, D. W. Oplinger, and J. J. Burke, Eds. Springer US, 1980, pp. 795-808.

[37] C. L. Soles, F. T. Chang, D. W. Gidley, and A. F. Yee, "Contributions of the nanovoid structure to the kinetics of moisture transport in epoxy resins," J. Polym. Sci. Part B Polym. Phys., vol. 38, no. 5, pp. 776-791, Mar. 2000.

[38] B. D. Harper, G. H. Staab, and R. S. Chen, "A Note on the Effects of Voids Upon the Hygral and Mechanical Properties of AS4/3502 Graphite/Epoxy,” J. Compos. Mater., vol. 21, no. 3, pp. 280-289, Mar. 1987.

[39] Z. Hashin, "Failure Criteria for Unidirectional Fiber Composites,” J. Appl. Mech., vol. 47, no. 2, pp. 329-334, Jun. 1980.

[40] P. P. Camanho, C. G. Dávila, S. T. Pinho, L. Iannucci, and P. Robinson, "Prediction of in situ strengths and matrix cracking in composites under transverse tension and in-plane shear," Compos. Part Appl. Sci. Manuf., vol. 37, no. 2, pp. 165-176, Feb. 2006.

[41] Z. Hashin, "Finite thermoelastic fracture criterion with application to laminate cracking analysis," J. Mech. Phys. Solids, vol. 44, no. 7, pp. 1129-1145, Jul. 1996.

[42] N. Carrère N., Tual, T. Bonnemains, E. Lolive, and P. Davies, "Coupled modeling of damage and sea-water absorption in carbon/epoxy laminates.”, submitted for publication in Compos. Sci. Technol. 


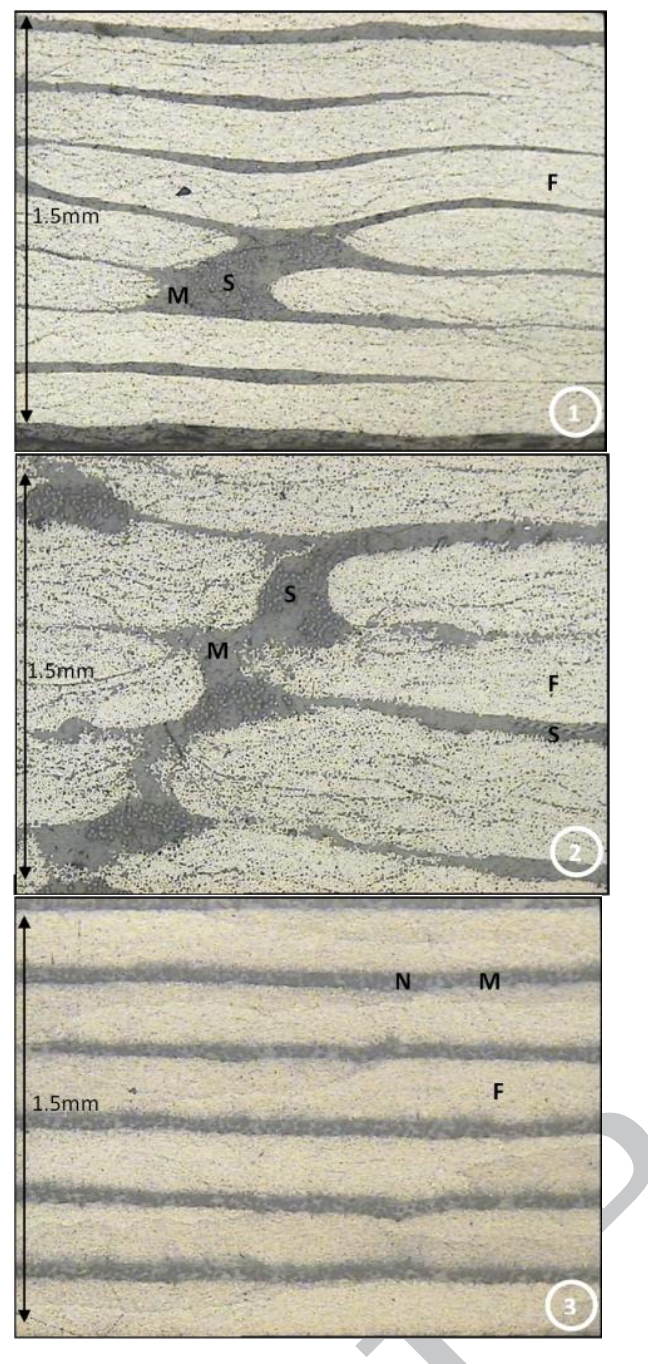

Figure 1. Optical microscope observation on UD samples, Infused (1), RTM (2) and Pre-preg (3) materials (magnification was X5, for all three materials). The different phases have been located, F: Fibres, M: matrix, S: Stitching, N: Nodules.

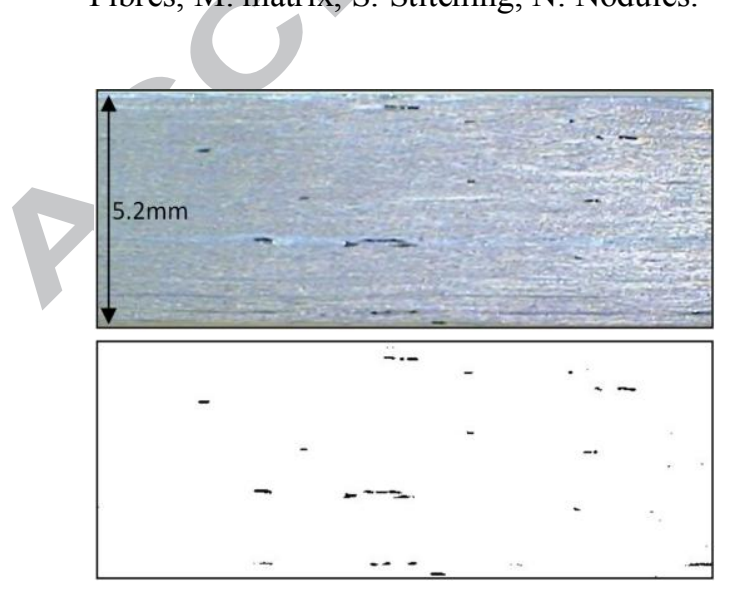

Figure 2. Example of micrograph of RTM UD $5.2 \mathrm{~mm}$ to determine porosity level. After image processing $\left(\right.$ Image $^{\mathrm{TM}}$ ) porosity levels were obtained, in this case $0.47 \% \pm 0.05$. 


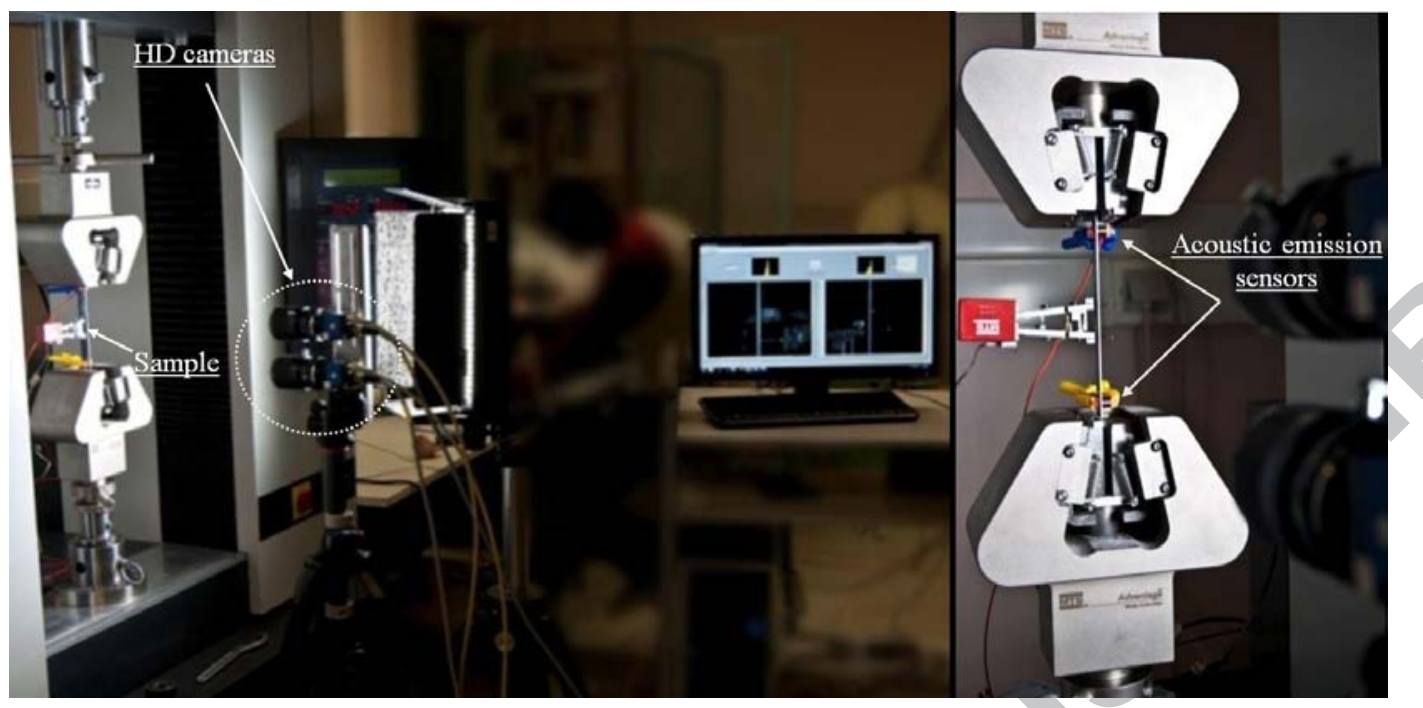

Figure 3. Test set-up to measure inter-fibre tensile cracking.
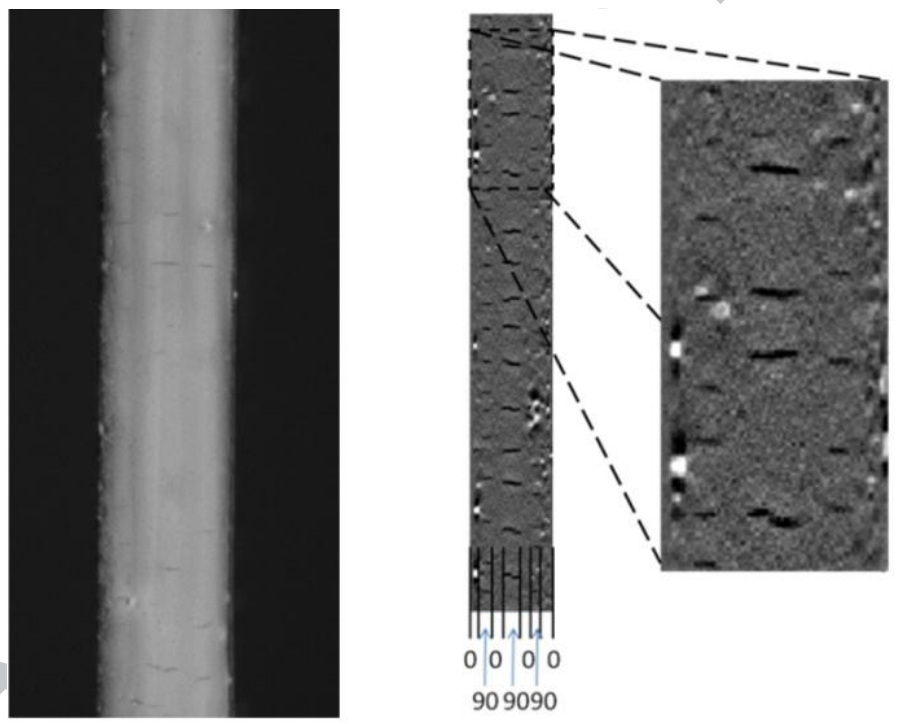

Figure 4. Visualization of cracks before (left) and after (right) Matlab ${ }^{\mathrm{TM}}$ processing (specimen thickness is $1.81 \mathrm{~mm})$. 


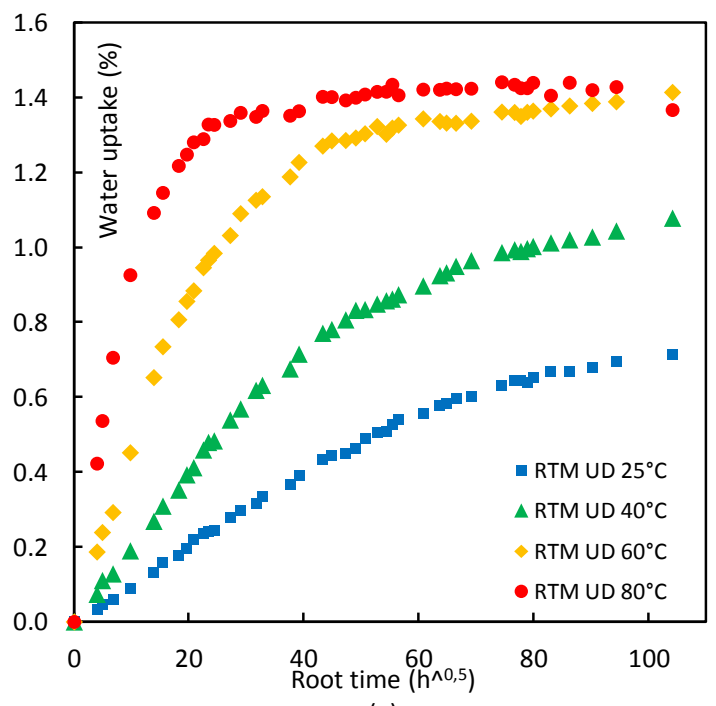

(a)

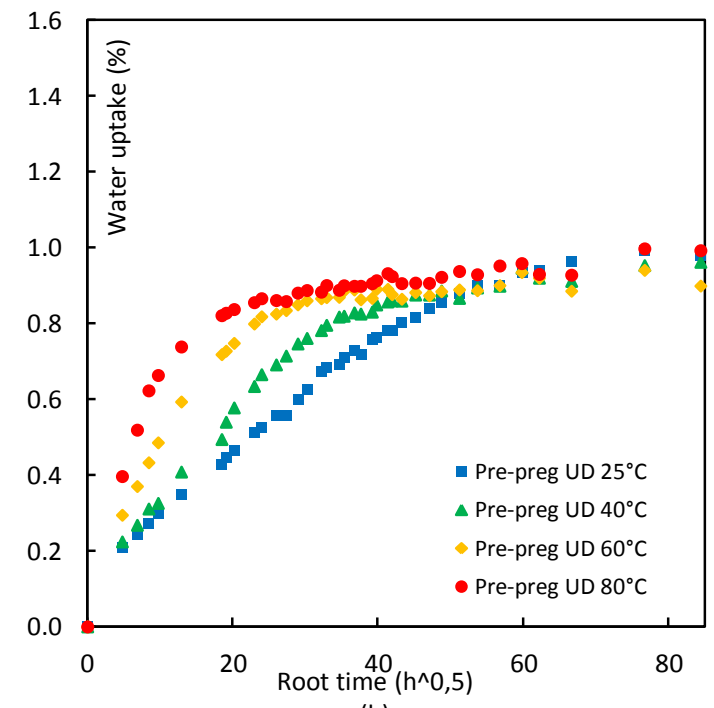

(b)

Figure 5. Plots of mean measured weight gains for RTM UD $2.5 \mathrm{~mm}$ (a) and Pre-preg $2.0 \mathrm{~mm}$ (b) at 25, 40,60 and $80^{\circ} \mathrm{C}$ during sea water immersion.

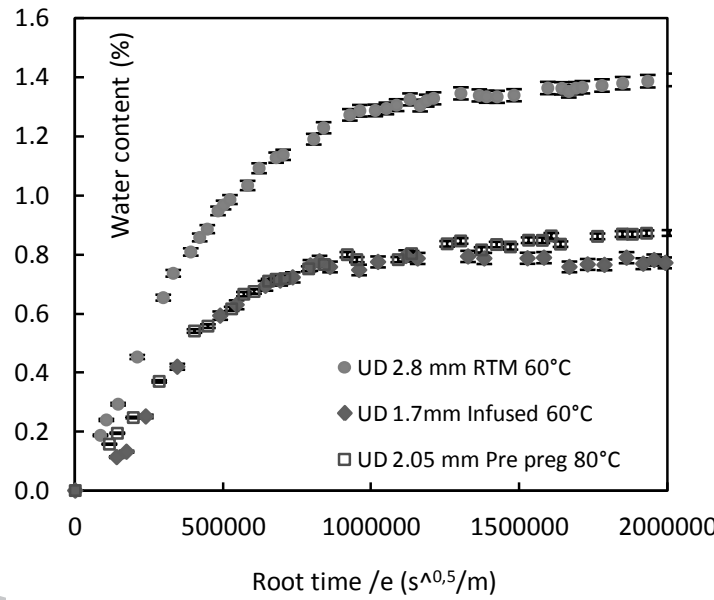

(a)

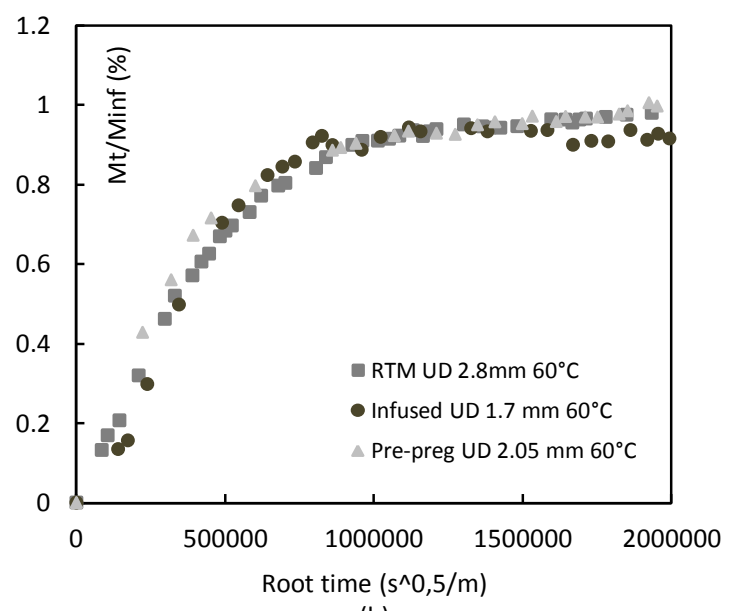

(b)

Figure 6. a) Plots of mean measured weight gains for RTM and Infused $60^{\circ} \mathrm{C}$ and Pre-preg composites at $80^{\circ} \mathrm{C}$ and b) plots of mean normalized weight gains for RTM, Infused and Pre-preg at $60^{\circ} \mathrm{C}$. 


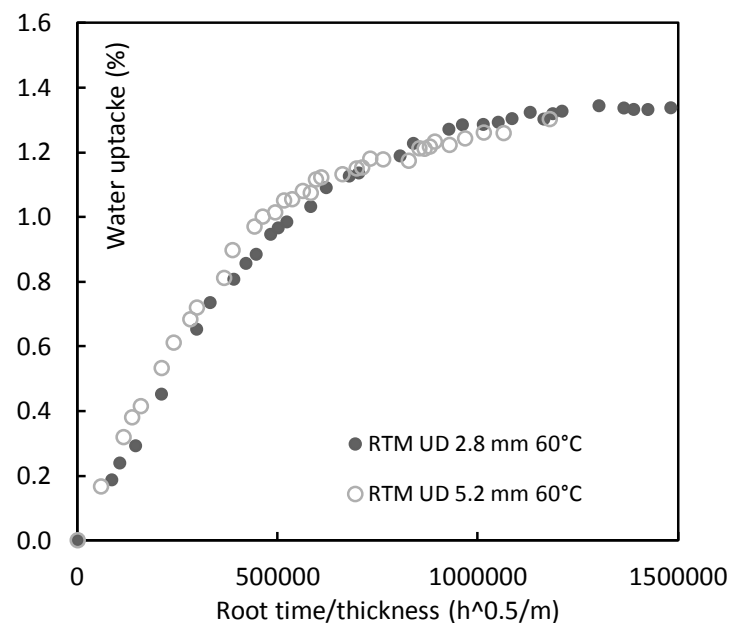

(a)

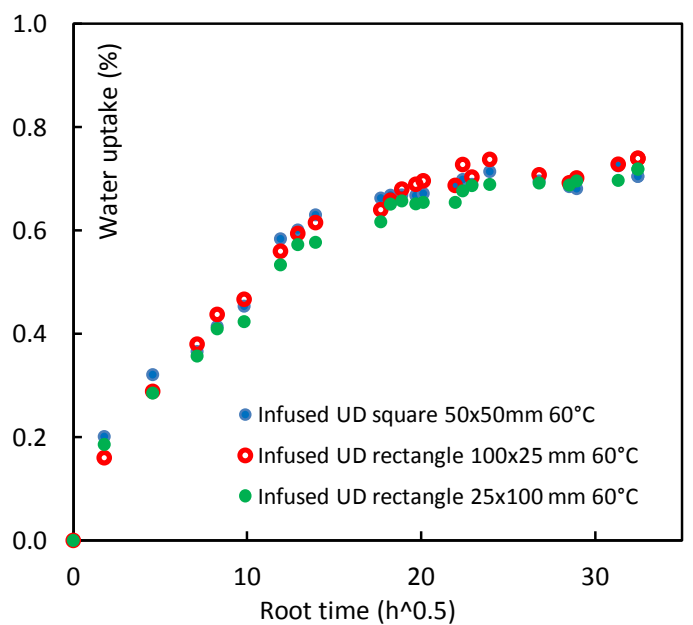

(b)

Figure 7. (a) Influence of sample thickness, comparison of mean measured weight gains for RTM UD $2.5 \mathrm{~mm}$ and UD $5 \mathrm{~mm}$ at $60^{\circ} \mathrm{C}$. (b) Influence of the geometry, comparison of mean measured weight gains for Infused UD.

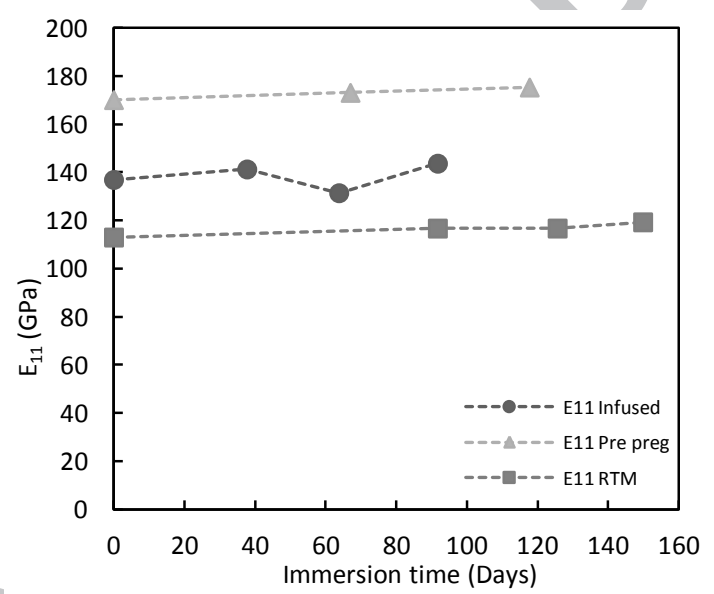

(a)

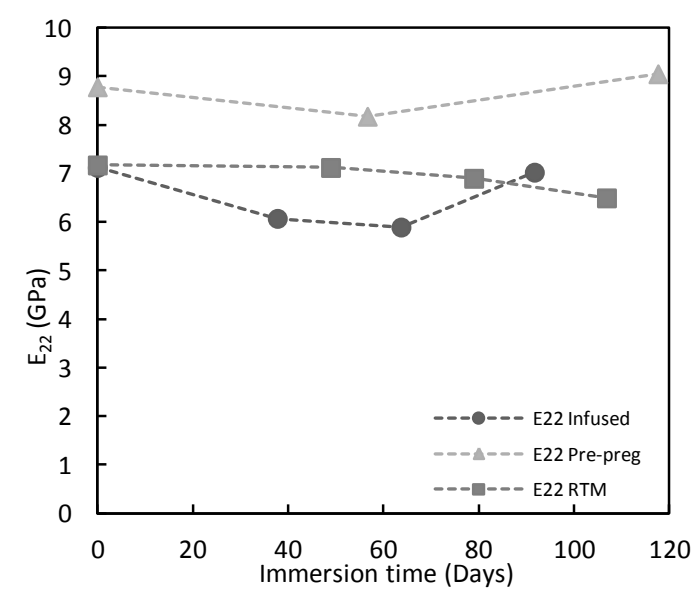

(b)

Figure 8. Plots of the evolution of mean longitudinal $\left(\mathrm{E}_{11}\right)(\mathrm{a})$ and transverse $\left(\mathrm{E}_{22}\right)$ (b) moduli for the three materials during accelerated sea water ageing. 


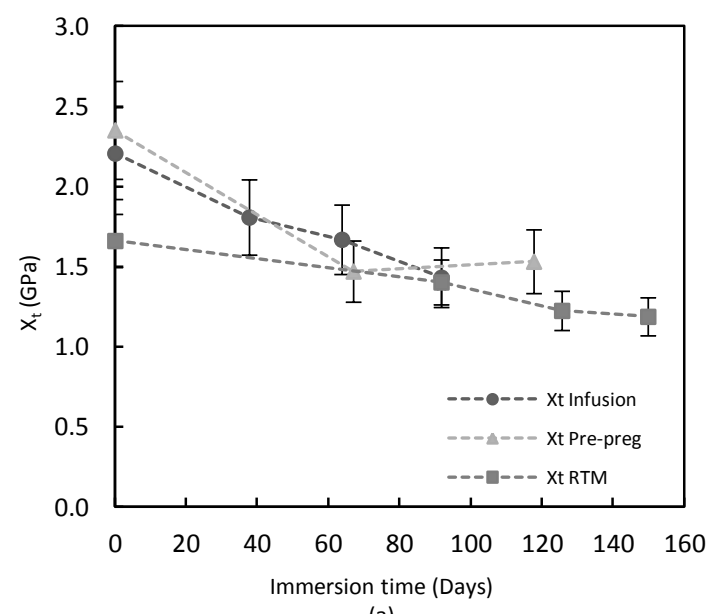

(a)

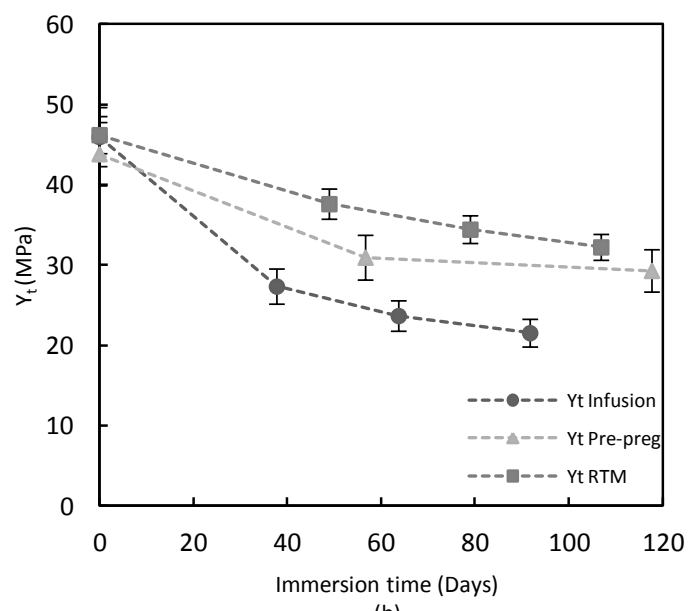

(b)

Figure 9. Plots of the evolution of mean longitudinal $\left(\mathrm{X}_{\mathrm{t}}\right)(\mathrm{a})$ and transverse $\left(\mathrm{Y}_{\mathrm{t}}\right)(\mathrm{b})$ tensile strengths for the three materials during accelerated sea water ageing. Scatter bars show standard deviations.

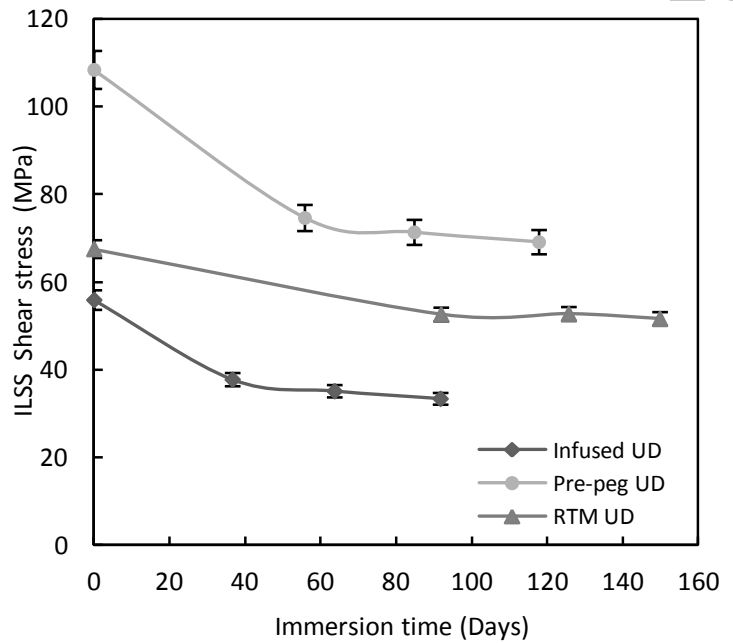

(a)

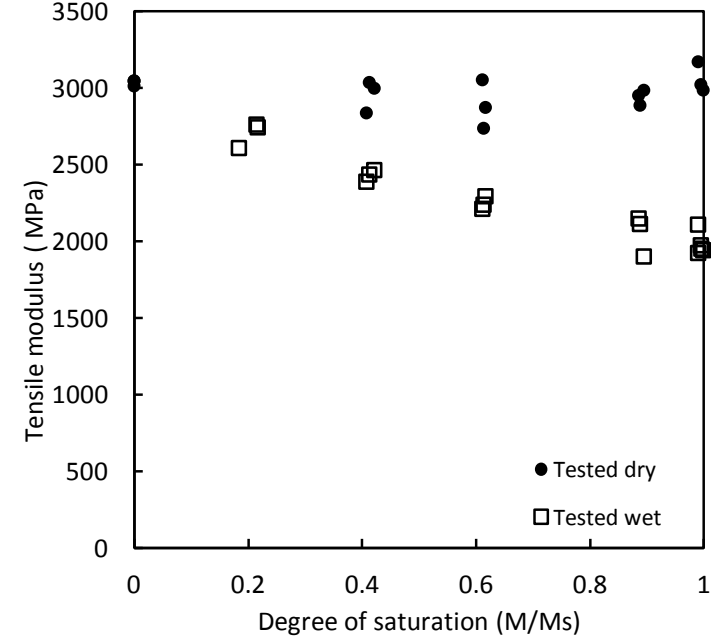

(b)

Figure 10. (a) Evolution of mean ILSS shear strength during sea water ageing at $60^{\circ} \mathrm{C}$ for three different UD materials. Scatter bars show standard deviations. (b) Evolution of matrix modulus as a function of the degree of saturation for resin specimens tested wet and the corresponding specimen aged and tested after drying. 


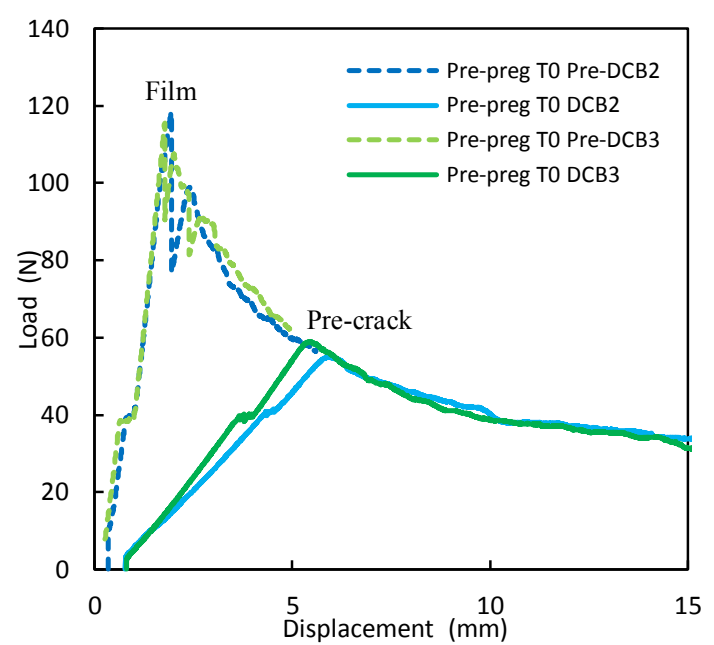

(a)

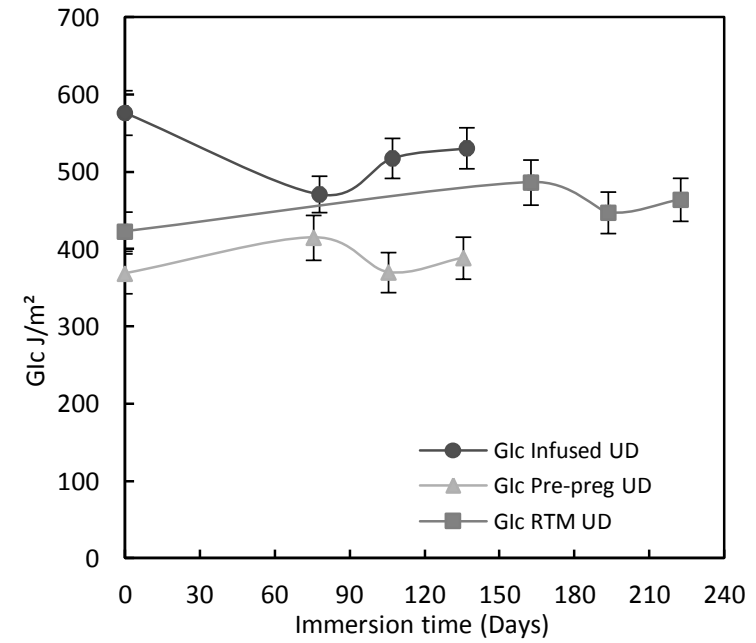

(b)

Figure 11. Mode I DCB tests. (a) Load-displacement plots from two specimens showing introduction of pre-crack and crack propagation from pre-crack on Pre-preg material and (b) evolution of critical strain energy release rate $\mathrm{G}_{\mathrm{Ic}}$ in carbon/epoxy Pre-preg, Infused and RTM materials during sea water ageing (b).

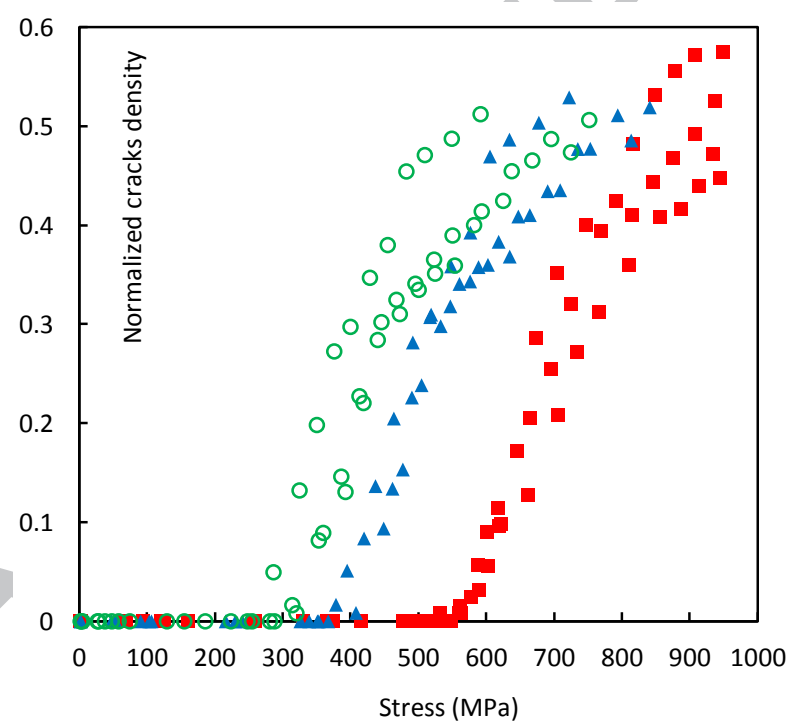

Figure 12. Evolution of normalized crack density for infused composite $\left[0_{2}, 90_{2}\right]_{\mathrm{s}}$ before ageing (red square), at saturation (blue triangle) and at saturation time plus one month (green circle) (3 specimens per condition). 


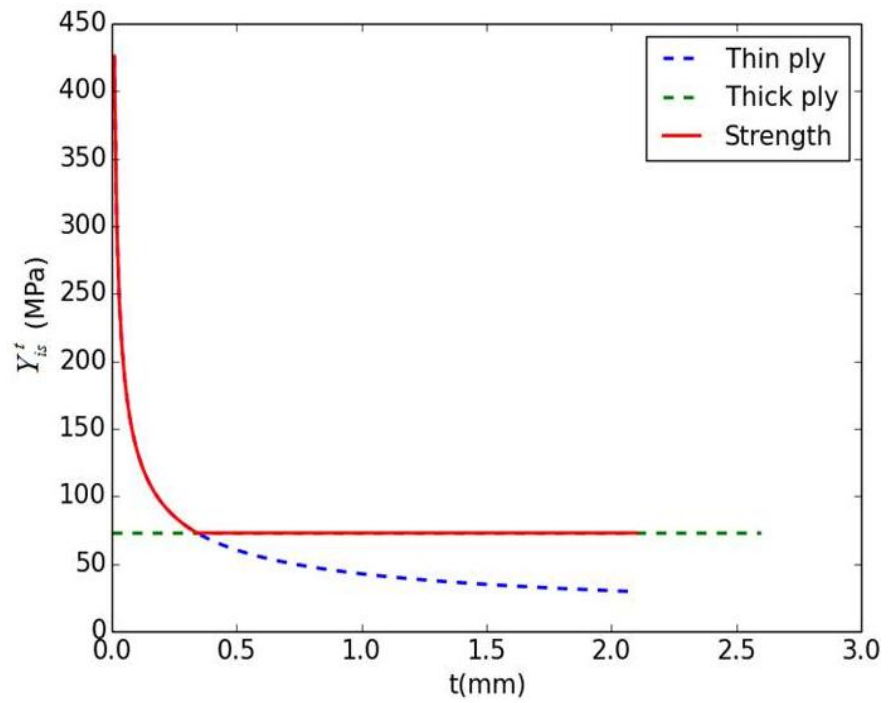

Figure 13. Evolution of the in-situ transverse tensile strength as a function of the ply thickness.

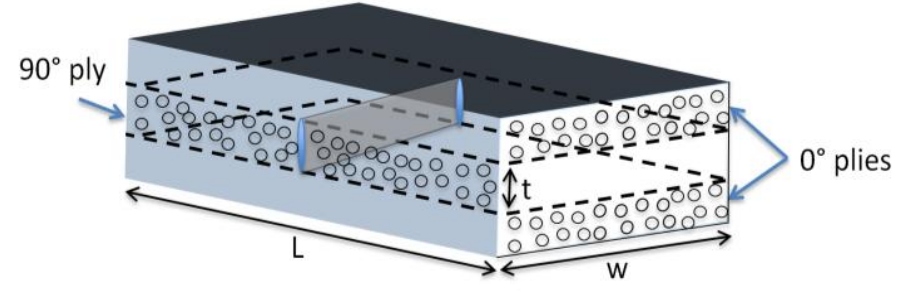

Figure 14. Representation of one intra-laminar crack and its surface. 


\begin{tabular}{cccc}
\hline Materials & Process & Resin & Fibre \\
Infused & Infusion & Infusion/RTM resin & Tenax-E IMS* \\
RTM & RTM low pressure & Infusion/RTM resin & Standard carbon fibre ** \\
Pre-preg & Autoclave 7 bar & Hexcel M21 & IMA \\
\hline
\end{tabular}

Table 1. Materials, process, resin and fibre compositions (*IMS: intermediate modulus, ** reference protected by industrial confidentiality).

\begin{tabular}{ccc}
\hline Materials & Curing condition & Tg \\
Infused & $16 \mathrm{~h} @ 65^{\circ} \mathrm{C}$ & $75^{\circ} \mathrm{C}(1.4)$ \\
RTM & $12 \mathrm{~h} @ 65^{\circ} \mathrm{C}$ & $77^{\circ} \mathrm{C}(2.0)$ \\
Pre-preg & $2 \mathrm{~h} @ 180^{\circ} \mathrm{C}$ & $195^{\circ} \mathrm{C}(2.1)$ \\
\hline
\end{tabular}

Table 2. Curing conditions and glass transition $(\mathrm{Tg})$ temperatures resulting for each material. 


\begin{tabular}{ccccc}
\hline Materials & $\begin{array}{c}\text { Thickness } \\
(\mathbf{m m})\end{array}$ & Orientation $\left(^{\circ}\right)$ & $\begin{array}{c}\text { Density } \\
\mathbf{( k g / \mathbf { m } ^ { \mathbf { 3 } } )}\end{array}$ & $\begin{array}{c}\text { Fibre volume fraction } \\
(\mathbf{\%})\end{array}$ \\
Infused UD & $1.73(0.02)$ & {$[0]_{8}$} & $1480(2)$ & $54.5(0.18)$ \\
Infused UD & $3.28(0.03)$ & {$[0]_{16}$} & $1492(2)$ & $56.3(0.24)$ \\
Infused QI & $1.75(0.02)$ & {$[+45,-45,0,90]_{\mathrm{s}}$} & $1475(2)$ & $52.3(0.19)$ \\
RTM UD & $2.81(0.06)$ & {$[0]_{8}$} & $1475(1)$ & $50.2(0.13)$ \\
RTM UD & $5.22(0.06)$ & {$[0]_{16}$} & $1493(3)$ & $52.7(0.22)$ \\
RTM QI & $2.91(0.05)$ & {$[+45,-45,0,90]_{\mathrm{s}}$} & $1462(2)$ & $48.1(0.21)$ \\
Prepreg UD & $2.05(0.08)$ & {$[0]_{8}$} & $1571(3)$ & $58.3(0.34)$ \\
Prepreg UD & $3.08(0.06)$ & {$[0]_{16}$} & $1563(2)$ & $56.6(0.28)$ \\
\hline
\end{tabular}

Table 3. Density measurements, estimated fibre content of studied materials, mean (standard deviation), thicknesses and orientation, UD (unidirectional) and QI (quasi-isotropic).

\begin{tabular}{ccc}
\hline Materials & Thickness $(\mathbf{m m})$ & ILSS $(\mathbf{M P a})$ \\
Infused UD & 1.7 & $55.9(0.2)$ \\
RTM UD & 2.8 & $67.5(0.9)$ \\
RTM QI & 2.9 & $48.3(0.4)$ \\
Prepreg UD & 2.0 & $93.3(2.7)$ \\
\hline
\end{tabular}

Table 4. ILSS test results on unaged composite materials (EN ISO 14130), mean (standard deviation), support span was $10 \mathrm{~mm}$ for all specimens presented. 


\begin{tabular}{cccc}
\hline RTM UD 90 $^{\circ}$ 2.8mm & T0 & T1 SW 60 $^{\circ} \mathbf{C ~ 4 8 ~ d a y s ~}$ & T1 Oven 60 $^{\circ} \mathbf{C ~ 4 8 ~ d a y s ~}$ \\
\hline E22 (GPa) & $7.17(0.01)$ & $7.24(0.15)$ & $8.10(0.32)$ \\
Yt(MPa) & $46.21(1.21)$ & $37.72(1.17)$ & $45.34(3.96)$ \\
\hline
\end{tabular}

Table 5: Comparison between effect of sea water (SW) and dry oven ageing on transverse tensile properties for RTM UD.

\begin{tabular}{ccccc}
\hline Materials & $\begin{array}{c}\text { Thickness } \\
(\mathbf{m m})\end{array}$ & $\begin{array}{c}\text { Diffusion coefficient } \\
\left(\mathbf{1 0 E}-\mathbf{1 3} \mathbf{~ m}^{2} \cdot \mathbf{s}^{-\mathbf{}}\right)\end{array}$ & $\begin{array}{c}\text { Ageing } \\
\text { temperature }\left({ }^{\circ} \mathbf{C}\right)\end{array}$ & $\begin{array}{c}\text { Max. Water } \\
\text { content }(\boldsymbol{\%})\end{array}$ \\
Infused UD & 1.7 & 4.7 & 60 & 0.80 \\
RTM UD & 2.8 & 5.3 & 60 & 1.33 \\
Prepreg UD & 2.0 & 4.5 & 80 & 0.86 \\
\hline
\end{tabular}

Table 6. Fickian diffusion coefficients for the three UD materials. 